\title{
Culturally relevant pedagogy for social work learning in Papua New Guinea: Perspectives from the University of Papua New Guinea's fieldwork programme
}

Dunstan Lawihin, University of Papua New Guinea

\begin{abstract}
INTRODUCTION: Social work education was introduced in the early 1970s in Papua New Guinea (PNG) and is still developing. Subsequently, its teaching and learning approaches have developed and, significantly, applied with greater flexibility than a standardised format although contemporary western methods predominate.

METHOD: The centrality of the PNG context for culturally relevant social work education and the paradigms of pedagogy in field education are discussed. PNG worldviews of teaching and learning have links to similar educational and practice perspectives from the Melanesian region, Pacific and other relevant non-western contexts.

CONCLUSIONS: PNG's ways of teaching and learning are yet to become formally integrated into contemporary social work education due to issues of credibility, relevance and quality assurance regarding professional social work values. The article argues for substantial integration and utilisation of traditional PNG-specific methods of teaching and learning in the delivery of social work education at the University of Papua New Guinea (UPNG) as important steps in developing the profession in the country. Indigenous local knowledge and practices of teaching and learning should become integrated into formal classroom pedagogical strategies in social work.
\end{abstract}

KEYWORDS: Melanesia; Papua New Guinea; cultural relevance; pedagogy; social work learning

AOTEAROA

NEW ZEALAND SOCIAL WORK 30(4), 40-55.

CORRESPONDENCE TO: Dunstan Lawihin dlawihin@upng.ac.pg
I am a tutor and researcher in social work of PNG/Melanesian origin writing within my own professional field and the sociocultural context of which I am a natural, indigenous citizen. I have been coordinating the Field Education programme at UPNG since 2010. The position taken in this article centres on my passion for developing culturally relevant social work education by connecting local and global commonalities and differences in order to appreciate the uniqueness of social work education and practice in PNG, relative to the Pacific region and further afield.

Culturally relevant social work education is a significant human right and social work educators should be ensuring that social work students have the opportunity to realise this right. Central to this argument is the expectation that social work education should be delivered using culturally relevant teaching and learning approaches that promote professional identity and cultural 
competence. Field education is an essential component of building a culturally relevant social work curriculum. In this article, where social work education is used broadly, field education is embraced as an integral aspect.

The development of a culturally relevant social work curriculum for PNG requires a rigorous empirical exploration of appropriate strategies for the localisation of global social work education standards and the incorporation of local knowledge and learning approaches. This article draws on relevant and accessible literature to discuss the significance of the PNG context in building culturally relevant social work pedagogy and paradigms for teaching and learning. Furthermore, my "insider" experiences and knowledge will be used to authenticate the significance of social work education and research for PNG in an increasingly globalised world.

This article endeavours to promote the development of culturally relevant social work education in PNG through the development and integration of indigenous pedagogical methods - through understanding PNG's social, political and cultural context and aligning local knowledge and practice principles that complement contemporary teaching and learning methods. First, PNG's political and socio-cultural context will be discussed followed by the examination of two key concepts indigenous to PNG culture: the Melanesian Way and Melanesian Pedagogy. The discussion on the Melanesian Way provides an understanding and contextualisation of conditions under which teaching and learning in social work field education occur, while the exploration of Melanesian Pedagogy lays the foundations for the identification of relevant PNG-specific pedagogies that can be adapted and applied for the effective delivery of contemporary social work field education.

\section{PNG context: development and transition}

PNG is a developing country and continues to explore development interventions for social and economic growth and prosperity. The Country Meters Information (2018) shows that PNG's total estimated population on 6 September 2018 was 8.15 million; growing at about 2\% annually. Australian Doctors International (ADI, 2015) reports that $87 \%$ of the population live in rural areas (51\% male, 49\% female). Life expectancy is 64 and 68 years for males and females respectively.

PNG has a young population $(60 \%$ are under the age of 25). The illiteracy rate is high and consistent with high levels of primary and secondary school dropout rates (ADI, 2015).

The predominant population in PNG is of Melanesian ethnicity. The Central Intelligence Agency (CIA) indicates that PNG is a Christian country with Roman Catholics comprising 27\%, Protestants $69.4 \%$, with $3.3 \%$ of population embracing indigenous beliefs (CIA, 2016). The three official languages for communication are Tok Pisin, English and Hiri Motu. Tok Pisin is widely used and understood, while English is spoken by 1-2\% of the population; less than $1 \%$ of people speak Hiri Motu (CIA, 2016).

The important challenge for PNG beyond these demographics is to ensure sustainable socioeconomic and environmental development amidst modernisation processes.

\section{Transition from traditional to contemporary PNG}

The pre-capitalist way of life in PNG emphasised small communities occupying a village or cluster of villages; kinship was the means of organising family and community life. Brydon and Lawihin (2013) maintain that PNG is still a nation in transition today. PNG has a history of colonisation dating from the 19th century and is Australia's only former colony. PNG achieved independence in 1975 and has since maintained a westernlike constitutional democratic system of government, with customary laws and its own Melanesian governance systems recognised by the country's National Constitution. 
Colonisation has taken its toll on PNG's cultural landscape, exposing vulnerabilities in many cultural practices and traditions. For example, tribal and social groupings initially had their own cultural practices and belief systems governing their livelihoods and promoting social wellbeing. Cultural knowledge and skills have remained the source of wisdom on which rural people depend for their livelihood especially where government services are non-existent.

While the colonial administration and missionaries were responsible for introducing western-oriented structures and values systems enjoyed today in PNG, Lovai (in press) argues that the initial integration of modern and traditional knowledge and value systems were not fairly considered. Thus, traditional and cultural knowledges have not been formalised and incorporated into modern knowledge systems in any integrated way.

Although PNG's National Constitution promotes western democratic values of human rights, equality of opportunity and individual freedom, it challenges the traditional PNG value of collective rights resulting in modern knowledge being accepted as superior to traditional knowledge - but Lovai (in press) contends that most people continue to value cultural knowledge in the form of PNG Melanesian wisdom. Such wisdom is fundamental for understanding local social issues and in navigating two different worlds with different sets of knowledge that co-exist in contemporary PNG.

\section{Situating field education in social work practice and education in PNG}

Field education is an integral component of professional social work education globally. Contemporary social work practice and education in PNG were introduced in the late 1960s and early 1970s respectively. Political self-governance and international pressure to have social work education introduced in Third World countries (O'Collins, 1993) are seen as the main drivers; however, traditional forms of governance welfare support were strong and existed prior to colonisation. Given the fickleness of political and social conditions over time, the focus of social work practice and education in PNG has evolved. Fundamental to this growth in social work education is the advancement of field education that connects knowledge to practice settings through research, policy, and practice

Social Work was offered under the Department of Anthropology \& Sociology

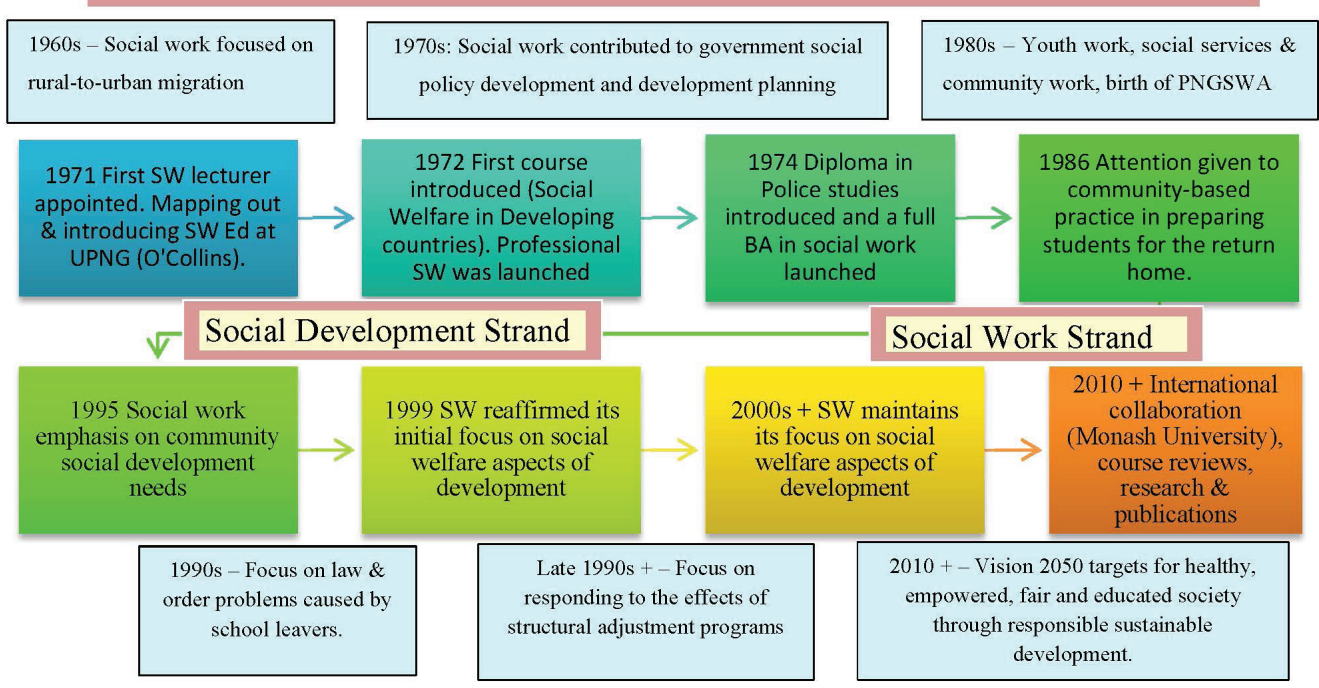

Figure 1. A timeline of social work development at UPNG and focus in PNG. Source: Lawihin (2017). 
and training interventions. Figure 1 shows the development of professional social work education and the focus of practice in PNG at the UPNG - the only university in the country offering social-work-specific studies.

To develop a training programme that addressed local needs and problems, O'Collins travelled widely in PNG and gathered stories and experiences of people and communities to firstly understand different local cultures (O'Collins \& Coleman, 2013). During the introduction of social work training and, after independence, social work education responded appropriately to emerging social issues. It should be recognised that students' fieldwork can play an important role in helping to address social challenges. For example, as experienced in fieldwork, the focus of social work education was on urban community development when there was increased rural-to-urban migration in the 1960s. In the 1970s, social work focused on contributing to government social policy developments and planning.

A school leavers' problem in the 1980s directed the focus of the UPNG Social Work programme (the programme) to youth work, social services and community work (Lovai, in press). However, youth work efforts could not effectively curb the increasing number of youth dropping out of school who by the 1990s, had become a serious law and order problem in urban areas. Social work education emphasised how to work with people, focused on meeting social needs and on the improvement of the social lives of both rural and urban communities. Towards the late 1990s, a restructure at the university set the context for the social work programme and its role in higher education as being:

...concerned with social welfare aspects of development and aims to enhance the quality of life of people in both rural and urban communities through the use of appropriate social work practices. It is also concerned with the application of social sciences to develop and to promote the wellbeing of the society. (UPNG, $1995 \mathrm{np}$ )
Although UPNG Social Work was developed with Melanesian communities in mind, most of the current curricular content and pedagogical approaches, including the models of practice taught, are of western origin. This works against any motivations to develop a unique model of culturally fit social work (Brydon \& Lawihin, 2014; Lawihin, 2017). These challenges continually exert pressure on the ability of social work to adequately respond to social, family and community needs and the needs of marginalised and vulnerable populations. Ensuring the appropriate application of relevant social work models supported by best practices is challenging. Therefore, the preparation of future social workers is critical, and such preparation should include tested knowledge and applied skills relevant to the local context.

The general oversight for the development and continuity of social work education and practice in any context is often provided by professional social work associations and academic institutions offering social work. In contexts where this is lacking, delivering social work educational programmes is a challenge. Flynn, Kamasua, and Lawihin (2016) describe social work in PNG as challenging in recent years due to limited academic and professional oversight. For example, although the Papua New Guinea Social Workers Association (PNGSWA) was established in the mid-1980s, it has remained less active since then. The programme was given international accreditation in 1974 by IASSW. While the IFSW (2014) still lists UPNG Social Work as a member organisation, Flynn et al. (2016) indicate that its accreditation status is unknown. Without the professional social work body, PNG is struggling to advance social work towards professionalisation.

\section{UPNG social work fieldwork}

As stated earlier, fieldwork is a critical component of the programme. The programme offers an undergraduate Bachelor of Arts (BA) in Social Work, as 
well as a postgraduate qualification. The fieldwork courses of this undergraduate degree and their details are presented in Table 1.

Social Work Practice (SWP) A and B are third-year courses offered annually and are delivered in concurrent mode, where students spend two days on placement culturally relevant approach to teaching and learning in PNG (Lawihin, 2017).

\section{Core aspects of culturally relevant pedagogy in PNG: the Melanesian Way}

The Melanesian Way is synonymous with the PNG Way and is a unique description of culture in Melanesian society that empowers

Table 1: UPNG Social Work Fieldwork Courses

\begin{tabular}{|l|c|l|c|c|}
\hline Year of study & Course number & Course name & Semester & Credit points \\
\hline $3^{\text {rd }}$ & 4.31017 & Social Work Practice A & 1 & 3 \\
\hline $3^{\text {rd }}$ & 4.31039 & Social Work Practice B & 2 & 3 \\
\hline $4^{\text {th }}$ & 4.41025 & Advanced Fieldwork & 2 & 6 \\
\hline BA Hons & 4.51028 & Honours Advanced Fieldwork & 2 & 3 \\
\hline
\end{tabular}

Source: UPNG Social Work Strand (2010).

and attend classes on other days each week. Advanced Fieldwork is taken in the fourth year. Fieldwork courses provide opportunities for students to learn and apply values, principles, knowledge, skills and attitudes and to gain practical experience in approved social work settings. In the two third-year SWP courses, students are expected to complete 26 days of practical placement (200 hours) and relevant coursework assessments. Advanced Fieldwork consists of 13 weeks of fulltime supervised professional fieldwork followed by a seminar presentation and the submission of a major (research) paper, making a total of 15 weeks. Advanced Fieldwork is undertaken when all the required social work courses have been successfully completed. The overall goal of the course is for students to develop the social work intervention skills required of a beginning social work graduate practitioner.

Fieldwork involves a multiplicity of organisations and people within the university and with agencies offering student placements. These agencies and supervisors are required to constantly collaborate with the university-based fieldwork coordinator and academics in order to collectively facilitate effective student learning. This is consistent with the Melanesian Way, and therefore is a and governs Melanesian communities (Narokobi, 1983). This culture is built on traditional values of communalism and collectivism across PNG, Fiji, New Caledonia, Solomon Islands and Vanuatu. The culture also defines the way teaching and learning occur and is centred on existing strong and intimate reciprocal relationships, which are integral tenets of Pacific Island cultures (Narokobi, 1983; Sanders, 1983; Vallance, 2007) and is distinctively different from the way relationships are constructed and valued in the western context.

In this article, the Melanesian Way is discussed from the PNG perspective in relation to other Pacific and non-western contexts. The Melanesian Way covers an array of unique beliefs, values and principlecentred systems that guide how Melanesians behave and interact with each other and their environments. This happens mostly among Melanesians themselves in the Melanesian region, although such collectivist cultures are found across the South Pacific (Faleolo, 2013; Mafile'o \& Vakalahi, 2016) and elsewhere such as in the Ubuntu Culture in Africa (Kreitzer, 2012; Mungai, Wairire, \& Rush, 2014) and in the Confucianism of the Chinese tradition (Liu, Sun, \& Anderson, 2013). Such collective cultures emphasise general collective responsibility 
- which includes teaching and learning. This is where field education can make a significant contribution to the development of culturally relevant social work education because it involves developing collective and collaborative interactions between the university, practice settings and the local community.

Melanesian Pedagogy is a subsidiary concept within the Melanesian Way which determines acceptable and appropriate teaching and learning methods. Such pedagogy is linked to the concept of culturally relevant pedagogy developed by Ladson-Billings (1995) that stresses the needs of students from various cultures. As we endeavour, as a nation and region, to develop culturally relevant pedagogy for Pacific Island students, Ladson-Billings' (1995) work can help us set the framework for teaching and learning in PNG. Gay (2000) and Ladson-Billings (1995) highlight five principles (identity and achievement, equity and excellence, developmental appropriateness, teaching the whole child, and studentteacher relationships), that set the basis for Melanesian Pedagogy in PNG.

Experiential evidence has shown that Melanesian Pedagogy is effective because students and teachers can easily relate to, and connect course content directly to, practical examples and pictorial images thereby demonstrating their understandings in class. Thus, using Melanesian Pedagogy highlights the need to integrate indigenous pedagogical strategies to enhance understandings of indigenous local knowledge and practices in teaching and learning (Lawihin, 2017). An example is the use of Tok Pisin and metaphors to explain complex social work models and discuss sensitive issues during fieldwork meetings. Furthermore, the participation of fieldwork supervisors in the UPNG programme has built Melanesian practice perspectives into the UPNG field education programme and helps to "bridge" professional practice expectations and academic standards.
Narokobi (1983) remains the most influential advocate of the Melanesian Way which critics have challenged as being suppressive, out-dated and irrelevant in the contemporary PNG context. While his knowledge base is philosophical, and thus possibly a less convincing source of information for practice and understanding in any scientific enquiry based on empiricism, Narokobi's ideas about the Melanesian Way are valuable to Melanesians because they value local knowledge, culture and identity. The Melanesian Way is also protected by PNG's National Constitution which lists, as Goal 5: The PNG Way. The PNG Way calls for any development in PNG to be achieved through building on and using PNG's forms of social, political and economic organisation. This constitutional basis provides further rationale for the integration of indigenous local knowledge and learning approaches into the formal education system. This can be done by adapting and incorporating positive aspects of community and the Wantok system (described later in this article) approach to learning such as the collaborative learning common in social work field education. Like other collectivist societies, community and personal lives in PNG are lived out through the key values of the community and the kinship system (Kreitzer, Abukari, Antonio, Mensah, \& Kwaku, 2009), which remain the core concepts of the Melanesian way, yet are not given prominence in contemporary learning and teaching approaches in PNG.

\section{The value of community as the centre of supporting social work learning in fieldwork at UPNG}

The community is the centre of life in Melanesia, and in PNG. Whilst there are clear boundaries regarding respect for elders, gender roles and hierarchical leadership power relations in PNG communities, life is characterised by reciprocal caring and sharing, which are also highly respected in teaching and learning. Maladede (2006) and Waiko (2007) as contemporary academics in PNG, re-emphasise that the Melanesian tradition is centred on principles of 
collectivism, egalitarianism and communal care and mutual support - also important in social work practice and education.

Maladede (2006) focuses on religious perspectives, highlighting the aspects of Melanesian culture that complement Christian values. For example, ideas about the shared responsibility of caring for the elderly extends beyond immediate kin to include other more distant members of the community. Maladede (2006, p. 5) states, "an individual living in a particular village is related in one way or another to every other person in the village". This assertion reinforces that Melanesian communities are highly characterised by values of caring and sharing arguably key tenets of a helping profession such as social work, highlighting the fit between the community and professional values promoted globally. The conclusion drawn from Maladede's views is that these positive Melanesian principles can be promoted and integrated into Christian knowledge development. Other Melanesian values, such as the application of the Wantok system and kinship are also consistent with contemporary religious and social ideals (Brydon \& Lawihin, 2014).

Waiko (2007), on the other hand, provides a historical perspective on Melanesian values. Waiko's views lead us to situate relationships, life and exchanges in terms of changes in the material context and lifestyle of Melanesian communities -here the focus is on communal wellbeing. This is where people work towards enhancing community wellbeing and the welfare of families rather than individuals. Because social work field education is delivered through shared responsibilities, among academics and field supervisors, the Melanesian community support system can be utilised to promote culturally appropriate learning.

However, neither writer discusses how these traditional Melanesian values can be, or are, applied in areas such as teaching and learning. This knowledge gap has been addressed in my recent study (Lawihin,
2017), drawing on the views of social work academics, students and fieldwork supervisors about how to develop a culturally relevant social work curriculum in PNG. Culturally relevant social work education in PNG is about connections, linkages and shared responsibility. This focus on relationships and exchanges in teaching and learning in social work education brings us to the concept of the Wantok system.

\section{Evaluating the Wantok system in the delivery of UPNG's social work field education}

The Wantok system is a traditional welfare support system based on kinship values. Wantok is a concept associated strongly with the closely-knit relationships in PNG. In the contemporary context, the term expresses an array of meanings such as "workmate," "business associate" or "a person from the same community." It has also retained its more traditional meaning, denoting a person from the same country, village or clan (Maladede, 2006). Therefore Wantok involves activities and interactions that occur and are undertaken along these relationships of sameness. Although, the Wantok system is arguably strong in PNG, close analysis of the system has revealed both negative and positive implications for contemporary development contexts, including social work education. The Wantok system's positive features are serving and mutual assistance and it is helpful because there is greater opportunity here for access to information and services based on the convenience of networks This is where teaching and learning in fieldwork can thrive on collaborative relationships between academics, students and field supervisors (Lawihin, 2017). Some fieldwork placements and learning opportunities provided to social work students have been conducted by utilising these existing, strong informal networks (Brydon \& Lawihin, 2014).

Conversely, the contemporary version of Wantok carries negative connotations that 
include a lack of independence, increasing liabilities and unwarranted payback. From a social work point of view, lack of independence poses risks in relation to maintaining professional ethics and confidentiality of information. It may even be associated with corruption and nepotism through gratuitous promotions and privileges (MacDonald, 1984; Maladede, 2006). Wantok may also inhibit initiative and responsibility, ultimately resulting in the emergence of ethnocentric enclaves indifferent or hostile to the wider society (MacDonald, 1984, p. 224).

Applying the Wantok system in social work teaching, learning and assessment, and particularly in fieldwork, could potentially undermine professional social work education and practice standards (IFSW, 2005), because it is often done in secrecy unless it is an open act of helping. Such collective and kinship practices are also evident in other contexts where local cultures have been shown to have a significant effect on the education and practice of social work (Clark \& Drolet, 2014; Gray, Kreitzer, \& Mupedziswa, 2014; Kreitzer, 2012; Yishak \& Gumbo, 2014).

Although community forms are undergoing change, the need for community as a place of support remains. The Wantok system acts like the social security model does in western societies. Thus, people depend on, take care of, and help each other. However, this system in the current state of public affairs offers community support in what appears to be new and foreign situations (Lawihin, 2017; Lovai, in press) driven by contemporary democratic idealistic governance - yet within PNG's Melanesian collective society and communalistic living arrangements.

Earlier research also supports the above analysis (Lawihin, 2012). This study sought to answer the question, "What should social work look like in PNG?" The research uncovered relevant information about the Melanesian Way with regard to social work field education. The study explored and documented the challenges of delivering fieldwork practicum at UPNG and established a list of factors that have influenced the use of various delivery approaches applied there. The findings indicated that aspects of the Melanesian Way present in the delivery and assessment of fieldwork had both positive and less positive ramifications for field education outcomes.

Positively, UPNG social work builds on the concept of Wantok when organising fieldwork placements, especially where no formal agreements have been entered into between UPNG and agencies. In addition, sharing, as the essential principle of the Melanesian way, is also reflected in how academics and fieldwork supervisors engage in shared responsibilities in training future social workers, again, often without formalised arrangements. The Melanesian Way also created a relaxed environment for students, providing time for reflective thinking and reporting. However, this relaxed environment led to both students and teachers not completing tasks in a timely manner. Furthermore, in terms of student assessment, the Melanesian Way views both teachers giving negative feedback and students asking critical questions as a bad thing. The latter is considered disrespectful towards lecturers and supervisors, although contemporary teaching and learning approaches encourage active student participation in the learning process.

In that study (Lawihin, 2012), I argued that, due to compelling local realities that favour the application of the Melanesian Way, less attention has been placed in the UPNG programme on embracing international field education standards. In a published account of that research (Brydon \& Lawihin, 2014), the authors concluded that some Melanesian approaches to fieldwork have undermined the professional tenets of social work. However, the study did not go so far as to highlight how that had happened or make suggestions for improvement. This presents an opportunity for further research in order to address this gap in Melanesian Pedagogy. 


\section{Melanesian Pedagogy for UPNG social work field education}

Melanesian Pedagogy is about teaching and learning methods and patterns in Melanesia, especially PNG in this case. Therefore, if pedagogy refers to an educator's teaching strategies and techniques, classroom management practices, evaluation methods, and ways of interacting with students (Tsang, 2006), then Melanesian pedagogical traditions are culturally specific strategies and techniques for teaching and learning in traditional Melanesia. Melanesian Pedagogy thus refers to Melanesian cultures, values, lifestyles and practices, and how these are uniquely expressed and lived in the context of learning. It concerns both the how (approaches), and the what (content), of knowledge that is transferred from the knower to the learner.

The following section reviews and discusses the existing knowledge on Melanesian teaching and learning in order to reestablish the basis for a relevant Melanesian Pedagogy in social work field education. There is evidence regarding the relevance of Melanesian worldviews of pedagogy for social work field education (Brydon \& Lawihin, 2014, 2013; Lawihin, 2017) and general pedagogy in Melanesia (Paschke, 2004). However, this area of research is still in its infancy, requiring more contributions. Subsequently, many of the materials reviewed are expert opinions, personal and professional accounts, and reflections of experts (including Brownlee, Farrel \& Davis, 2012; Guthrie, 2015; Hahambu, Brownlee, \& Petriwskij, 2012; Narokobi, 1983; Waldrip, Taylor, \& Wilikai, 2012), along with traditional local knowledge drawn from my own experiences, backed by similar cultural knowledge from sources elsewhere. The discussion begins with a focus on historical context and the introduction of formal education in PNG.

\section{Education approaches in PNG: formal and traditional}

Education involves teaching and learning as the core elements of knowledge transfer and acquisition. In all societies, both formal and traditional forms of education coexist. Prior to the Second World War, formal education was not considered important for the indigenous population and was left to the missions and churches (Megarrity, 2005). The 1950s and 1960s marked a period of distinct focus on education where largely westernised Australian educational values and models were introduced. Megarrity (2005) describes this as "blending the cultures" (p. 5). During the 1960s and 1970s, the education system in PNG went through changes taking the form it is in today, without any real decolonisation of the introduced educational policy, frameworks and curriculum, which are still predominantly western.

Guthrie (2015), an educational expert, presents a controversial argument about ideal educational practices in PNG. He argues that traditional cultural practices of knowledge sharing are a close fit with formalistic education practices, because both are teacher-centred and rely on accepted dynamics of expert and student. He describes PNG as having a revelatory epistemology, where knowledge comes from deities and the ancestors - and where knowledge is transmitted - not discovered by the student. From this position, knowledge is to be accepted not challenged, and, "The task of the learner [is] to look and to listen to people who [are] known to be trustworthy" (p. 36). Guthrie talks about different styles of traditional education highlighting the role of storytelling and the important role of experts and observation albeit indirectly.

He summarises the argument by saying that:

Numerous elements of traditional education, especially formal education involving sacred knowledge, anticipated the formalistic classroom teaching that was introduced in the colonial period in PNG. One key element was that the traditional paradigm was revelatory. This is consistent with an underlying 
element in modern formalism, where the assumption also is that the teacher knows and transmits and the student does not know and receives. A second key element was that the learner's job was to find people who had knowledge and would teach it, which schools now institutionalise. (p. 42)

Although Guthrie's arguments concern primary/secondary education, it is apparent that all students come through this system and are primed, both educationally and culturally, toward particular ways of learning. He argues that there are established cultural reasons for teacher-centred learning, where students often do not ask questions and where knowledge is passed on from expert to student - often using storytelling and observation of specific skills. He argues that, rather than trying to change this, we should improve existing formalistic classroom practice.

Lindstrom (1984) presents information regarding the development of these ideas, identifying Melanesian approaches to teaching as either operational (instructive) or interpretive (explanatory). These early arguments are similar to what Guthrie (2015, p. 36) describes as:

...informal education, through which much knowledge is passed, usually from an older person to a younger one within the family or clan, but also among peers and often through story-telling [interpretive - explanatory].

And

...non-formal education, where knowledge is passed from experts in a particular field such as gardening, fishing, sago making or tribal warfare, for example; to others who are learning these skills on the job [operational instructive].

Operational knowledge is used in rituals, initiations and other behaviour in the form of instructions from the possessor of such knowledge, while the latter concerns expertly organising ideas and presenting them meaningfully to audiences. The application and transfer of these forms of knowledge is predominantly verbal.

Oral knowledge sharing (storytelling and recital) is accompanied by metaphors, modelling, signs and imagery. Learning in PNG has been and continues to be through listening, observation, memorising and imitating (Interchurch Organization for Development Cooperation (ICCO) \& German Development service (DED), 2004); Lindstrom 1984). These Melanesian instructional approaches are analysed in the following section, with consideration of their application to social work field education.

\section{Melanesian pedagogical strategies for fieldwork}

Although the pedagogical strategies discussed here are not unique to PNG, the aspect needing further exploration and understanding is how these approaches are enacted in field education and in what context they are effective. Paschke's (2004) work on traditional Melanesian learning patterns for cross-cultural learning highlights strategies common across many areas of Melanesia that reinforce the major informal learning patterns that are also dominant in PNG's traditional learning space, yet are significant places for the development of culturally relevant knowledge based in a contemporary social work education context. He highlights observation, imitation, listening, participation, and enquiring as common Melanesian learning methods. The following discussion examines storytelling and the language of instruction, metaphors, modelling and observation for integration into current fieldwork learning at UPNG.

\section{Storytelling as a teaching method for fieldwork meetings and seminars}

Oral history is the source from which Melanesian communities draw their 
identities and proclaim their origins. As a mode of instruction, story is about developing and transferring knowledge and is acquired through listening, memorisation, reflection and recitation. Diverse forms of stories (stori) exist in Melanesia and serve different purposes.

Fostering knowledge through storytelling was emphasised in a small project in PNG (ICCO \& DED, 2004), which sought to develop an indigenous organisational development approach for NGOs. ICCO and DED reflect on their PNG experiences of developing and implementing a PNG approach to organisational learning and development in the NGO sector. Their case study was based on the local knowledge and experiences of PNG organisational development facilitators. They argued, similar to Guthrie (2015), that there was strong acknowledgement that story-telling is PNG's strongest and most utilised learning and teaching style, although not isolated to Melanesian cultures alone (Paschke, 2004). They concluded that storytelling is critical in building the capacities of local organisations.

This case study claims that stories are a highly developed art form for negotiations, passing on information about history and genealogy, land matters, rituals and relationships, and peace building among families, groups and villages. Storytelling therefore has become the main approach for transferring knowledge and a favourite tool for teaching and learning in PNG. Faleolo (2013) similarly highlights the significance of storytelling in social work teaching and learning in contemporary Samoa, making specific reference to the Talanoa phrase aileI' $a$, which means talking. He emphasises talking through issues directly with students to help them make meaning of the context and to understand the nature of problems. This enables students to develop an understanding of relevant strategies and possible solutions.

There is also evidence from a broader human psychology perspective supporting the value of stories in education. Green
(2004), an authority in human psychology, stresses the importance of stories in the classroom-learning context, claiming that stories can be used to spark student interest, aiding the flow of lectures, making material memorable, overcoming student resistance or anxiety, and building rapport between the instructor and the students, or among students themselves. Sharing knowledge and experiences through stories has been an inevitable part of human history and forms part of everyday conversations in both informal contexts and more structured contexts such as in formal conferences, meetings and school settings.

Furthermore, Alterio's (2002) experiences in school settings highlight that storytelling in formal teaching and learning contexts has multiple benefits. Storytelling is an ideal teaching and learning tool because it enables students to make sense of their own experiences and views, to link theory to practice and to stimulate their critical thinking skills. Storytelling further provides a way to enhance relationships between students, where they create new knowledge and learning from each other; the students and teachers can learn about themselves and their surroundings. According to Alterio (2002), storytelling only becomes meaningful when processes and activities incorporate opportunities for reflective dialogue, foster collaborative endeavour, nurture the spirit of inquiry and contribute to the construction of new knowledge. Besides, cultural, contextual and emotional realities are acknowledged, valued and integrated into storytelling. As a mode of inquiry, student learning is enhanced when storytelling is used in a robust manner. All these contributions make a strong case for stories to form a key learning strategy for fieldwork students to reflect on their experiential learning experiences in formal classroom settings - field education is an experiential form of teaching and learning that takes place in a social service setting.

The key question related to developing a Melanesian Pedagogy in social work field education is: "In what form, shape and 
style should story occur in classroom and placement settings?" There is also recent evidence (Ilai, 2012) suggesting that the language of instruction also affects the quality of learning and feedback. According to Ilai, the level of thinking, reflection, feedback and understanding of the meaning of a story are flexible and depend on the language used

\section{Tok Pisin as language of instruction in field education}

The choice of language for instruction is critical to student learning. PNG is culturally and linguistically diverse, making the choice of language for instruction problematic. With more than 830 different spoken languages, PNG has the highest linguistic diversity in the world (McCarthy, 2015), however, only three are official languages - English, Motu and Tok Pisin. Most villages and tribal populations speak and understand their specific mother tongue. Mother tongue is often restricted to specific locations and cultural boundaries. English is mostly used in formal settings and in classrooms, while Tok Pisin (Melanesian Pidgin) is becoming popular among those with greater exposure to modern lifestyles and urban communities. A recent study (Lawihin, 2017) reveals that Tok Pisin is increasingly becoming PNG's most commonly spoken language in many informal social settings. Two other studies (Gure, 2010; Ilai, 2012) also confirm that Tok Pisin is increasingly used in elementary schools as the language of instruction in both rural and urban PNG despite English remaining the main language of instruction in formal schooling.

The current trend is that Tok Pisin is used more frequently and by most Papua New Guineans than English or Motu. Tok Pisin is also emerging as the language of business, including teaching and learning. From the UPNG Social Work Field Education example, all the key stakeholders are Tok Pisin users and most use English only when in lecture rooms and engaging in formal conversations. UPNG social work students and most of the field educators use Tok Pisin in all other personal and group interactions. In the practice context, ICCO and DED (2004, p. 29) argue that the use of Tok Pisin in organisational development work is considered "indigenous to Melanesia because some of the tools and concepts of organisational development are named and described in Tok Pisin."

The above evidence presents a significant argument that Tok Pisin is a culturally relevant language of instruction in PNG and therefore the UPNG Social Work Programme could benefit from utilising it in field education. The next section focuses on the use of metaphors - a form of oral story that can further enhance student learning.

\section{Metaphors (tokpiksa) for enhanced fieldwork instruction and learning}

Metaphors are analogies or parables. Anecdotal observations suggest that metaphors are an integral part of purposive daily communication in Melanesia yet more research is required in this area. ICCO and DED (2004) suggest that metaphors are more often used for diplomatic reasons in PNG, for confidentiality purposes or to show respect to someone when communicating sensitive topics. According to ICCO and DED, common metaphorical communication in PNG is the language of adults and happens in strategic rituals and events. The application of metaphors in the organisational development context suggests an indirect transfer of information that the recipients require to engage in deep reflection, analysis and discussion which are also important in social work field education.

Metaphors are best applied to broach direct criticisms in a learning environment. As indirect methods for communicating sensitive matters, metaphors allow educators and students to reflect on their experiences and learning. ICCO and DED (2004) argue that Papua New Guineans tend not to say things which openly and directly criticise those controlling knowledge. This has 
led to challenges for field educators who struggle to provide constructive criticism and negative feedback to students. Although the work of ICCO and DED focused on facilitator reflections and did not utilise a robust and systematic methodology for data collection and analysis, this source is practical and locally relevant and therefore adds value to the current discussion.

Elsewhere, Mouraz, Pereira, and Monteiro (2013) found that metaphors could effectively be used in explaining and interpreting scientific events to produce knowledge in teaching and learning in higher education. The authors concluded that analogical reasoning and metaphors are vehicles for learning, and they recognised their pedagogical power to enhance students' motivation and to deepen knowledge production and acquisition. This finding is valuable because it focuses on metaphors as vehicles for learning in a course offered in a specific university context such as social work field learning at UPNG. Pramling (2011) similarly notes that the use of metaphors is relevant in learning in the science field, and in primary and secondary education. Empirical research (Northcote \& Fetherston, 2006) however, indicates that conceptualising metaphors and figurative stories is often difficult and requires deeper reflective thinking, reading between the lines and critical analysis to uncover the essence of the behaviour portrayed in the story. For social work, this is positive because metaphors can help students and their teachers develop deep, complex, varied parallel and integrated understandings about the processes of teaching and learning in fieldwork. Magalhães and Stoer (2007) study metaphors as key approaches employed in teaching and learning, using case studies to investigate their mode and effectiveness as interpretive and explanatory models in the learning process.

Haggis (2004) considers that metaphors can be used to shape thoughts and action in both creative and restrictive ways. However, her study was limited to students' views on teaching and learning in order to understand how the nature and meaning of learning is articulated differently. In a related area, both Jensen (2006) and Pitcher (2013) used metaphors as a research method, concluding that such an approach allows for the development of a more nuanced understanding of the social context of the issue being examined. This evidence is supportive of efforts in PNG to develop culturally relevant social work field education.

Faleolo (2013, p. 109) notes the importance of parable as a form of metaphor in the development of social work curriculum with a strong representation of cultural content and knowledge. While this opinion may be questioned for its empirical validity, the argument is that parables reveal significant culturally valid knowledge, which can develop an understanding of specific cultures' knowledge and practices. Yet, metaphoric communication in PNG is not often utilised in formal teaching and learning; an element that needs further investigation so that metaphors are fully utilised as a recognized Melanesian learning strategy.

Whilst metaphors and analogies are valuable learning strategies, imitation and observation have also been an integral part of PNG, Melanesian learning culture.

\section{Modelling (imitation) and observation to enhance fieldwork learning}

Imitation and observation have long been traditional methods of teaching and learning in PNG that complement oral literature and metaphors. It is important to recognise that imitation and observation emphasise skills development and acquisition because they are technical and involve action. They also provide the opportunity for applying knowledge by imitating or responding through direct learning encounters. Modelling and observation are some of the most utilised teaching and learning methods in 
contemporary education and training and are supported by wider scholarship and theory, including the work of Bandura (McLeod, 2016) on social learning theory, and Kolb on experiential learning theory (Kolb \& Kolb, 2011). According to Clark, Threeton, and Ewing (2010), Kolb's model involves four modes of grasping experience: concrete experience, reflective observation, abstract conceptualisation, and active experimentation. While educators may prefer one mode to introduce to their students first, Clark et al. (2010) refer to Kolb and Fry's (1975) comment that "the learning process can begin for students at any one of the four modes and should be viewed as a continuous cycle" (p. 49). These pedagogies can work effectively in field education.

Craig, Vanlehn, Gadgil, and Chi (2006) point to collaboratively observing tutoring as a promising method for observational learning. Although observational learning is essential during childhood, the principles may also be applicable to adult students. Ilai (2012) and Gure (2010), highlight this consistency with traditional Melanesian culture where oral "literature," observation, and learning by practice and imitation are dominant sources of building knowledge and establishing experience. However, the effect of these activities on learning is enhanced by multiple other alternatives including the use of images, artefacts, and metaphors to uncover deeper, inner and intuitive knowledge or expand on existing knowledge (Gure, 2010). The use of stories and metaphors in traditional knowledge transfer gives essence and meaning to the signs and images in understanding a wide range of community life, history, culture and nature. Drawings and carvings, on the other hand, are often used for historical and genealogical purposes. These cultural symbols are useful traditional knowledge representations in PNG and can effectively be used in supervision and reflective sessions as learning strategies in field education to enrich students' experiences in fieldwork.
Such cultural pedagogies and historical knowledge can add value to social work education, with an emphasis on the historical development of social work and the protection of signature social work values. Therefore, imitation and observation are "culturally fit" learning and teaching approaches for PNG and participants across the Pacific.

\section{Conclusion}

In the search for a culturally relevant pedagogy for social work (field) education, I have highlighted the approaches to contemporary teaching and learning in educational research and practice. This article has discussed the Melanesian way and its related concepts (community and the Wantok system) as overarching domains for culturally relevant learning strategies which connect to Melanesian learners. The article also deliberated on several aspects of Melanesian pedagogies in order to shape future research. I have highlighted the integration of Melanesian Pedagogy to contemporary methods of instruction for social work field education including community-oriented learning approaches and pedagogies such as storytelling, the use of metaphors, observations and imitation as potential enhancers of social work teaching and learning. This initial discourse is a first step towards developing and delivering culturally relevant social work education that considers traditional approaches to knowledge acquisition as integral to contemporary fieldwork learning and teaching, formal teaching and supervision of social work students in PNG.

\section{References}

Alterio, M. (2002). Understanding storytelling to enhance student learning. The Higher Education Academy. Retrieved from http://desarrollodocente.uc.cl/images/ Innovaci\%C3\%B3n/Storytelling/Alterio_M._2003.pdf

Australian Doctors International. (ADI). (2015). Annual Report 2015-2016. Australian Doctors International, NSW. Retrieved from www.adi.org.au

Brownlee, J. M., Farrel, A., \& Davis, J. (2012). Understanding learning and teaching in Papua New Guinea: Elementary teacher trainers engaged in cultural authorship in the context of national education reforms. Australian Journal of Education, 37(2). Retrieved from http://ro.ecu.edu.au/ ajte/vol37/iss2/2 
Brydon, K., \& Lawihin, D. (2013). The current situation in social work education in Papua New Guinea. Advances in Social Work and Welfare Education, 15(2), 69-83.

Brydon, K., \& Lawihin, D. (2014). Melanesian visions: Some preliminary thoughts about social work education and practice in Papua New Guinea. International Social Work, 59(2), 192-204. doi:10.1177/002087281351501

Central Intelligence Agency (CIA). (2016). World Factbook: East and Southeast Asia: Papua New Guinea. Retrieved from https://www.cia.gov/library/publications/the-worldfactbook/geos/pp.html

Clark, N., \& Drolet, J. (2014). "Melq'ilwiye" Coming together: Reflections on the journey towards indigenous social work field education. Currents: Scholarship in the Human Services, 13(1), 1-22.

Clark, R., Threeton, M., \& Ewing, J. (2010). The potential of experiential learning models and practices in career and technical education \& career and technical teacher education. Journal of Career and Technical Education, 25(2), 46-62.

Country Meters Information. (2018). Papua New Guinea population. Retrieved from https://countrymeters.info/en/ Papua_New_Guinea

Craig, S. D., VanLehn, K., Gadgil, S., \& Chi, M. T. H. (2006). Learning from collaboratively observing videos during problem solving with Andes. In R. Luckin, K. R. Koedinger, \& J. Greer (Eds.), Artificial intelligence in education (pp. 554-556). Amsterdam, Netherlands: IOS Press.

Faleolo, M. (2013). Authentication in social work education: The balancing act. In C. Noble, M. Henrickson, \& I. Y. Han (Eds.), Social work education. Voices from the Asia Pacific (2nd ed., pp. 105-132). Sydney, NSW: Sydney University Press.

Flynn, C., Kamasua, K., \& Lawihin, D. (2016). Aspirations and realities in delivering field education in a developing country context: Learning from Papua New Guinea. In I. Taylor, M. Bogo, M. Lefevre, \& B. Teater (Eds.), Routledge international handbook of social work education (pp. 209-219). Abingdon, UK: Routledge.

Gay, G. (2000). Culturally responsive teaching: Theory research, and practice. New York, NY: Teachers College Press.

Gray, M., Kreitzer, L., \& Mupedziswa, R. (2014). The enduring relevance of indigenization in African social work: A critical reflection on ASWEA's legacy. Ethics and Social Welfare, 8(2), 101-116.

Green, M. C. (2004). Storytelling in teaching. The Association of Psychological Science, 17(4), 52-54.

Gure, R. (2010). Tok pisin and internal variation. Griffith Working Papers in Pragmatics and Intercultural Communication, 3(1), 1-11.

Guthrie, G. (2015). Culturally grounded pedagogy and research methodology. Compare: A Journal of Comparative and International Education, 45(1), 163-168. doi:10.1080/03057925.2014.981440

Haggis, T. (2004). Meaning, identity and motivation: Expanding what matters in understanding learning in higher education? Studies in Higher Education, 29(3), 323-336.

Hahambu, C., Brownlee, J. M., \& Petriwskyj, E. A. (2012). Elementary teacher education in Papua New Guinea: Towards a culturally connected perspective of teaching.
Australian Journal of Teacher Education, 37(4). http:// dx.doi.org/10.14221/ajte.2012v37n4.4

Ilai, D. S. (2012). Simbu's untold tales: A case study on oral stories in Tabare language. Journal of Linguistic Society of Papua New Guinea, Language \& Linguistics in Melanesia, 30(2), 59-67.

Interchurch Organization for Development Cooperation (ICCO) \& German Development Service (DED). (2004). Organization in focus: A Papua New Guinean approach to organization development. Interchurch Organization for Development Cooperation.

International Federation of Social Workers. (2005). Global standards for the education and training of the social work profession. International Journal of Social Welfare, 14, 218-230.

International Federation of Social Workers. (2014). Global definition of social work. Retrieved from http://ifsw.org/ policies/definition-of-social-work/

Jensen, D. F. N. (2006). Metaphors as a bridge to understanding educational and social contexts. International Journal of Qualitative Methods, 5(1), 1-17.

Kolb, D.A. \& Fry, R.E. (1975). Toward an applied theory of experiential learning. In C. Cooper (ed.), Theories of group processes. (pp. 33-55) N.Y.: John Wiley \& Sons.

Kolb, A. Y., \& Kolb, D. A. (2011). Experiential learning theory: A dynamic, holistic approach to management learning, education and development. Retrieved from https://www.researchgate.net/profile/ David_Kolb/ publication/267974468_Experiential_Learning_ Theory_A_Dynamic_Holistic_Approach_to_ Management_Learning_Education_and_Development/ links/5559122408ae6fd2d826eb12.pdf

Kreitzer, L. (2012). Social work in Africa: Exploring culturally relevant education and practice in Ghana. Calgary, Alberta: University of Calgary Press.

Kreitzer, L., Abukari, Z., Antonio, P., Mensah, J., \& Kwaku, A. (2009). Social work in Ghana: A participatory action research project. Social Work Education: The International Journal, 28(2), 145-164.

Ladson-Billings, G. (1995). But that's just good teaching! The case for culturally relevant pedagogy. Theory into Practice, 34(3) 159-165.

Lawihin, D. (2012). Shaping the future of student fieldwork in social work education at UPNG. Applied Research Study Report. Melbourne, VIC: Department of Social Work, Monash University.

Lawihin, D. (2017). Building a culturally relevant social work curriculum in Papua New Guinea: connecting the local and global in field education. (Unpublished Masters thesis), Monash University, Melbourne, VIC.

Lindstrom, L. (1984). Doctor, lawyer, wiseman, priest: Bigman and knowledge in Melanesia. Man, New Series, 19(2), 291-309.

Liu, M., Sun, F., \& Anderson, G. S. (2013). Challenges in social work field education in China: Lessons from the western experience. Social Work Education: The International Journal, 32(1), 179-196.

Lovai, B. (in press). Social work and society. In Social Work in Papua New Guinea in the Last 50 Years (1965-2015).

MacDonald, M. (1984). Melanesian communities past and present. In D. Whiteman, (Ed.), An introduction to Melanesian cultures (pp. 213-230). Goroka, PNG: The 
Melanesian Institute. Retrieved from http://www.mi/org/ pg/Pages/Point/Melanesian\%20Institute\%20

Mafile'o, T., \& Vakalahi, H. F. O. (2016). Indigenous social work across borders: Expanding social work in the South Pacific. International Social Work, 1-16. doi:10.1177/0020872816641750.

Magalhães, A., \& Stoer, S. (2007). Europe as a bazar: A contribution to the analysis of the reconfiguration of nation-states and new forms of "living together." In C. Torres, \& A. Teodoro (Ed.), Critique and utopia: New developments in the sociology of education in the twenty-first century (pp. 65-86). Mitchellville, MD: Rowman \& Littlefield Publishers.

Maladede, M. (2006). Let Christ be a Melanesian: A study of Melanesian key values. East Asian Pastoral Review 43(1). Retrieved from http://eappi.admu.edu.ph/contentlet-christ-be-menanseian-keyvalues

McCarthy, N. (Statista Charts). (2015). The countries with the most spoken languages, https://www.statista. com/chart/3862/the-countries-with-the-most-spokenlanguages/

McLeod, S. (2016). Bandura - Social learning theory. Retrieved from http://www.simplypsychology.org /bandura.htm

Megarrity, L. (2005). Indigenous education in colonial Papua New Guinea: Australian government policy (1945-1975). History of Education Review, 34(2), 41-58.

Mouraz, A., Pereira, A. V., \& Monteiro, R. (2013). The use of metaphors in the processes of teaching and learning in higher education. Journal of Educational Sciences, 5(1), 99-110.

Mungai, N., Wairire, G. G., \& Rush, E. (2014). The challenges of maintaining social work ethics in Kenya. Ethics and Social Welfare, 8(2), 170-186.

Narokobi, B. (1983). Life and leadership in Melanesia. Institute of Pacific Studies, University of South Pacific and University of Papua New Guinea.

Northcote, M. T., \& Fetherston, T. (2006). New metaphors for teaching and learning in a university context. Paper presented at the Higher Education Research and Development Society of Australasia) Conference, Perth Australia. Retrieved from http://www.herdsa.org.au/wpcontent/uploads/conference/2006/papers/Northcote.pdf

O'Collins, M. (1993). Social development in Papua New Guinea 1972-1990: Searching for solutions in a changing world. Political and Social Change Monograph 18. Canberra, ACT: Australian National University.

O'Collins, M., \& Coleman, L. (2013). Last of the lands we know: Recollection of the life and times of Maev O'Collins (joint publication with Dr Les Coleman). Brisbane, QLD: Connor Court Publishing.

Paschke, J. (2004). The small group as a learning environment for teaching Melanesian Christians: Issues for the cross-cultural facilitator. Melanesian Journal of Theology, 20(2), 54-78.

Pitcher, R. (2013). Using metaphor analysis: MIP and beyond. Qualitative Report, 18(68), 1-8.

Pramling, N. (2011). Possibilities as limitations: A study of the scientific uptake and moulding of G. A. Miller's metaphor of chunk. Theory and Psychology, 1-21. doi:10.1177/0959354310380492

Sanders, D. (1983). Pacific developments: Implications for future directions in American social work.
International Social Work, 26(2), 9-18. doi: https://doi. org/10.1177/002087288302600203

Tsang, N. M. (2006). Dialectics-The arts of teaching and learning in social work education. Social Work Education: The International Journal, 25(3), 265-278.

University of Papua New Guinea. (1995). Social development information and course for 1995. Port Moresby: School of Humanities and Social Sciences, University of Papua New Guinea.

University of Papua New Guinea. (2010). Social work strand information and course for 2010. Port Moresby: School of Humanities and Social Sciences, University of Papua New Guinea.

Vallance, R. J. (2007). A Melanesian research methodology. Contemporary PNG Studies: DWU Research Journal, 7, 1-15.

Waiko, J. (2007). A short history of Papua New Guinea (2nd ed.). South Melbourne, VIC: Oxford University Press.

Waldrip, B. G., Taylor, T. J., \& Wilikai, W. (2007). Pedagogic principles in negotiating cultural conflict: A Melanesian example. International Journal of Science Education, 29(1), 101-122.

Yishak, D. M., \& Gumbo, M. T. (2014). Indigenising the curricula in Ethiopia from a Gamo Ethnic Group perspective: The case of constitutional, policy and strategy provisions. Mediterranean Journal of Social Sciences, 5(10), 185-197. 